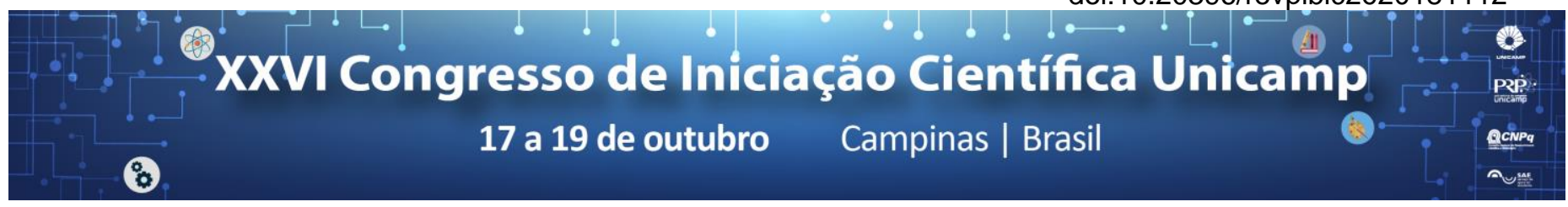

\title{
N-GAL na avaliação do perfil de alterações renais em pacientes com síndromes falciformes.
}

\author{
Paolla Ravida A. de Macedo*,Sara Teresinha Olalla Saad,Fernanda Orsi, Laís Quinteiro Tobaldini,Célia Regina \\ Garlipp, Bruno D.Benites, Paula V. Bottini, Simone Cristina O.Gilli.
}

\begin{abstract}
Resumo
O envolvimento renal na doença falciforme compreende uma gama de desordens glomerulares e tubulares sendo sua incidência diretamente proporcional ao aumento da sobrevida dessa população sendo importante causador de morbidade e mortalidade desses pacientes. Os distúrbios renais nas doenças falciformes podem apresentar-se de forma assintomática, ou através de sinais como hematúria. Envolvidos na fisiopatologia desses eventos estão diversos mecanismos, como alterações na concentração e acidificação urinárias, microtromboses e infarto renal. A isquemia medular pode levar a inabilidade em manter o gradiente de íon hidrogênio, levando a uma forma incompleta de acidose tubular renal distal (tipo IV), que pode estar associada a hipercalemia independente da aldosterona. Há escassez de dados na literatura avaliando hipercalemia e acidose tubular renal especificamente em pacientes portadores de síndromes falciformes. Pouco se sabe também sobre a melhor maneira de avaliar a função renal nesse grupo de pacientes, cuja doença é caracterizada, nos estágios iniciais, por hiperfluxo glomerular, levando a falsas estimativas do real acometimento da função dos rins. Há escassez de dados na literatura avaliando hipercalemia e acidose tubular renal especificamente em pacientes portadores de síndromes falciformes. O objetivo deste estudo é fazer esse diagnóstico, e analisar a eficiência do N-GAL(Neutrophil Gelatinase Associated Lipocalin) para este diagnóstico.
\end{abstract}

\section{Palavras-chave: \\ Anemia Falciforme, Disfunção renal, Acidose Tubular.}

\section{Introdução}

A hiperfiltração glomerular e a incapacidade de concentrar urina, também denominada hipostenúria, são as anormalidades renais mais precoces em pacientes com anemia falciforme geralmente sem repercussões clínicas evidentes. Contribui para a piora da função renal a isquemia medular que pode levar a inabilidade em manter o gradiente de íon hidrogênio, levando a uma forma incompleta de acidose tubular renal distal (tipo IV), que pode estar associada a hipercalemia independente da aldosterona [1]. Dessa forma, acompanhando a hipostenúria, pode ocorrer acidose tubular distal, apresentando-se ou não com hipercalemia, dependendo da existência de condições que prejudiquem os mecanismos compensatórios renais [2]. As equações que estimam a função renal, mostraram-se de baixa acurácia para detecção precoce de comprometimento renal em pacientes com síndromes falciformes.

NGAL é uma proteína pequena encontrada tanto nos neutrófilos quanto em certos epitélios, como os túbulos renais, e o aumento de sua produção está associado ao esforço de regeneração. A função fisiológica de NGAL nos rins é desconhecida, no entanto, acredita-se que tenha um papel na morfogênese renal. A produção do NGAL aumenta nos casos de lesão renal, de qualquer etiologia, se elevando rapidamente tanto no plasma como na urina após o início da lesão ou do processo de lesão renal, o que o classifica como o marcador mais precoce para lesões renais, tendo sensibilidade e especificidade altas[3].

Este estudo tem por objetivo determinar a prevalência de acidose tubular renal distal tipo IV em pacientes com Anemia Falciforme atendidos no Hemocentro da Unicamp, mapear as principais alterações bioquímicas relacionadas a doença, e analisar a eficiência do N-GAL no diagnostico precoce.

\section{Resultados e Discussão}

Foram avaliados 10 pacientes com doença falciforme e hipercalemia(5H:5M;idade média38,6) e 10 controles com doença falciforme sem hipercalemia (5H:5M; idade média 41,8).

Pudemos observar que a comparação entre pacientes com hipercalemia e sem resultou em:

\begin{tabular}{lccc}
$\begin{array}{l}\text { Diagnóstico de } \\
\text { Doença Falciforme }\end{array}$ & $\begin{array}{c}\text { Pacientes com } \\
\text { hipercalemia }\end{array}$ & $\begin{array}{c}\text { Pacientes sem } \\
\text { hipercalemia }\end{array}$ & P Valor \\
\hline K sérico mEq/L & $5,15 \pm 0,57$ & $4,2 \pm 0,45$ & 0.001 \\
\hline K urinário mEq/L & $26 \pm 10,2$ & $24,5 \pm 11,3$ & 0.838 \\
\hline Na mEq/L & $136 \pm 1,9$ & $138 \pm 2,7$ & 0.1 \\
\hline Na urinário mEq/L & $91 \pm 33,9$ & $80,5 \pm 47,5$ & 0.604 \\
\hline Uréia mg/dL & $31,5 \pm 54$ & $28,5 \pm 14$ & 0.762 \\
\hline Creatinina mg/dL & $0,79 \pm 1,465$ & $0,79 \pm 0,187$ & 0.733 \\
TFG mL/min/1,72m2 & $118,51 \pm 57,244$ & $118,635 \pm 40,274$ & 0.631 \\
\hline OSMOLAL & $291,5 \pm 11,9$ & $290,5 \pm 5,9$ & 0.909 \\
mOsmol/KgH2O & & & \\
OSMOLALURI & $375 \pm 113,9$ & $408,5 \pm 80,3$ & 0.391 \\
mOsmol/KgH2O & & & \\
TTKG & $3,61 \pm 1,218$ & $4,722 \pm 1,8251$ & 0.497 \\
N-Gal ng/mL & $8 \pm 55,47$ & $6,5 \pm 49,84$ & 0.463
\end{tabular}

\section{Conclusões}

Dados de literatura já demonstram que exames laboratoriais como creatinina, ureia e taxa de filtração glomerular estimada, não são bons preditores de comprometimento precoce da doença renal em pacientes com doença falciforme. Observamos que na nossa casuística os pacientes com hipercalemia apresentavam aumento na ureia, creatinina, e taxa de filtração glomerular, entretanto, acreditamos que estas alterações tenham acontecido no momento em que a insuficiência renal esteja atingindo estágio crônico. É imperativo o emprego de um marcador precoce de piora da função renal para instituição da terapêutica adequada. No entanto o marcador N-Gal dentro na nossa casuística não se mostrou efetivo na detecção da disfunção renal, nem da acidose tubular tipo IV.

1.Alhwiesh, A., An update on sickle cell nephropathy. Saudi J Kidney Dis Transpl, 2014. 25(2): p. 249-65.

2. Lopez Revuelta, K. and M.P. Ricard Andres, Kidney abnormalities in sickle cell disease. Nefrologia, 2011. 31(5): p. 591-601

3. 30.RONCO C, N-GAL: diagnosing AKI as soon as possible. Crit Care. $2007 ; 11(6): 173$ 